\title{
X-RAY PHOTOELECTRON STUDY OF ELECTRON DENSITY DISTRIBUTION IN PALLADIUM(II) $\beta$-DIKETONATE COMPLEXES
}

\author{
L. N. Mazalov, ${ }^{1,2}$ S. V. Trubina, ${ }^{1,2}$ \\ N. A. Kryuchkova, ${ }^{1}$ O. A. Tarasenko, ${ }^{1}$ \\ S. V. Trubin, ${ }^{1}$ and G. I. Zharkova ${ }^{1}$
}

UDC 539.193:539.194

\begin{abstract}
This work is devoted to experimental (X-ray photoelectron) and theoretical investigations of electron density distribution in $\operatorname{Pd}(\mathrm{II}) \beta$-diketonate complexes. Data about the electronic structure (effective charges, core level energies) of the compounds are compared with their thermodynamic parameters (thermal stability, vaporization enthalpy). In molecular crystals of $\mathrm{Pd}(\mathrm{II}) \beta$-diketonates, the volatility of the complexes and vaporization enthalpy $\Delta H_{T}^{0}$ depend not only on van der Waals interactions, but also on electrostatic interactions of molecules in crystal.
\end{abstract}

Keywords: X-ray photoelectron spectroscopy (XPS), Pd(II) $\beta$-diketonates, electronic structure and thermodynamic properties of complexes.

\section{INTRODUCTION}

Volatile metal $\beta$-diketonates of the general formula $\mathrm{M}\left(\mathrm{R}^{1} \mathrm{COCHCOR}^{2}\right)_{n}(\mathrm{M}$ is the metal, and $\mathrm{R}$ are the terminal substituents) are now widely used for solving various technological problems in isolation of pure metals by metal-organic chemical vapor deposition (MOCVD) processes. Volatility and its dependence on the electronic structure of complexes are very important properties of these compounds. As is known [1], the standard thermodynamic parameters such as vaporization enthalpy $\Delta H_{T}^{0}$ and entropy $\Delta S_{T}^{0}$ are determined by the nature of the terminal substituents $\mathrm{R}^{1}$ and $\mathrm{R}^{2}$ in the ligand. The thermal stability of $\mathrm{Pd}(\mathrm{II})$ complexes of $\beta$-diketonates with different terminal substituents was investigated in [2, 3]. It was shown that the thermodynamic parameters of the crystal-vapor phase transition depend on the energy of van der Waals intermolecular interactions of $\beta$-diketonate complexes in crystals. The energy of intermolecular interactions, in turn, depends on the character of electron density distribution in the molecule [4-6].

X-ray photoelectron spectra (XPS) provide information about the charged states of atoms in the molecule and about the distribution of electron density over the atoms of the compound in relation to the nature of the terminal groups of ligands [7-9]. The aim of the present work is to study experimentally and theoretically the peculiarities of electron density distribution in $\mathrm{Pd}(\mathrm{II}) \beta$-diketonates and to compare data about the electron structure (effective charge, core level energy) and the thermodynamic parameters (vaporization enthalpy $\Delta H_{T}^{0}$, thermal stability) of the compounds. For terminal radical

\footnotetext{
${ }^{1}$ A. V. Nikolaev Insitute of Inorganic Chemistry, Siberian Division, Russian Academy of Sciences, Novosibirsk; svt@che.nsk.su. ${ }^{2}$ Novosibirsk State University. Translated from Zhurnal Strukturnoi Khimii, Vol. 48, No. 2, pp. 259-268, March-April, 2007. Original article submitted November 2, 2006.
} 


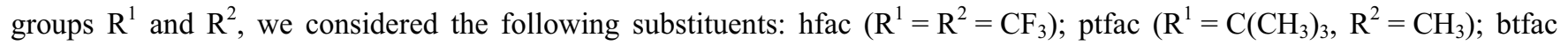
$\left(\mathrm{R}^{1}=\mathrm{C}_{6} \mathrm{H}_{5}, \mathrm{R}^{2}=\mathrm{CH}_{3}\right) ; \operatorname{dmp}\left(\mathrm{R}^{1}=\mathrm{R}^{2}=\mathrm{C}\left(\mathrm{CH}_{3}\right)_{3} ; \mathrm{dbm}\left(\mathrm{R}^{1}=\mathrm{R}^{2}=\mathrm{C}_{6} \mathrm{H}_{5}\right) ;\right.$ bac $\left(\mathrm{R}^{1}=\mathrm{C}_{6} \mathrm{H}_{5}, \mathrm{R}^{2}=\mathrm{CH}_{3}\right) ;$ acac $\left(\mathrm{R}^{1}=\mathrm{R}^{2}=\mathrm{CH}_{3}\right)$.

\section{EXPERIMENTAL CONDITIONS AND THEORETICAL CALCULATIONS}

To study electron density distribution on atoms of $\mathrm{Pd}(\mathrm{II}) \beta$-diketonate complexes in this work we recorded X-ray photoelectron spectra of the $\mathrm{Pd} 3 d_{3 / 2,5 / 2}, \mathrm{C} 1 s, \mathrm{O} 1 s$, and $\mathrm{F} 1 s$ atoms of the compounds (Fig. 1). The spectra were studied on a VG-Microtech X-ray photoelectron spectrometer at room temperature and residual gas pressure of $10^{-7}$ Torr; transmission energy of the energy analyzer was $50 \mathrm{eV}$. For photoelectron excitation, we employed an X-ray tube with an aluminum anode ( $h v=1486 \mathrm{eV}$ ) with $U=10 \mathrm{kV}, I=20 \mathrm{~mA}$. The spectrometer was calibrated against the positions of the photoelectron peaks of the $\mathrm{Au} 4 f_{7 / 2}(84.0 \mathrm{eV})$ and $\mathrm{Cu} 2 p_{3 / 2}(932.7 \mathrm{eV})$ core levels. The background was taken into account by Shirley's procedure [10]. The spectra were decomposed into components using the XPS PEAK 4.1 program. The line shape was approximated with Lorentz-Gaussian mixed functions (Fig. 1). The energy positions of the maxima of the spectral lines were determined to an accuracy of $0.2 \mathrm{eV}$.

Electronic structure calculations were fulfilled for a series of $\operatorname{Pd}(\mathrm{II}) \beta$-diketonate complexes (Fig. 2) with the Jaguar v.6.5 package of quantum chemical programs [11] at the level of density functional theory (DFT) using the B3LYP hybrid exchange correlation functional in the LACVP $\mathrm{G}^{* *}$ and $3-21 \mathrm{G}^{*}$ basis sets. Geometry optimization was performed based on the crystal data of [12]; the interatomic distances and bond angles were obtained with an accuracy of $0.05-0.07 \AA$ and $1.5^{\circ}$,
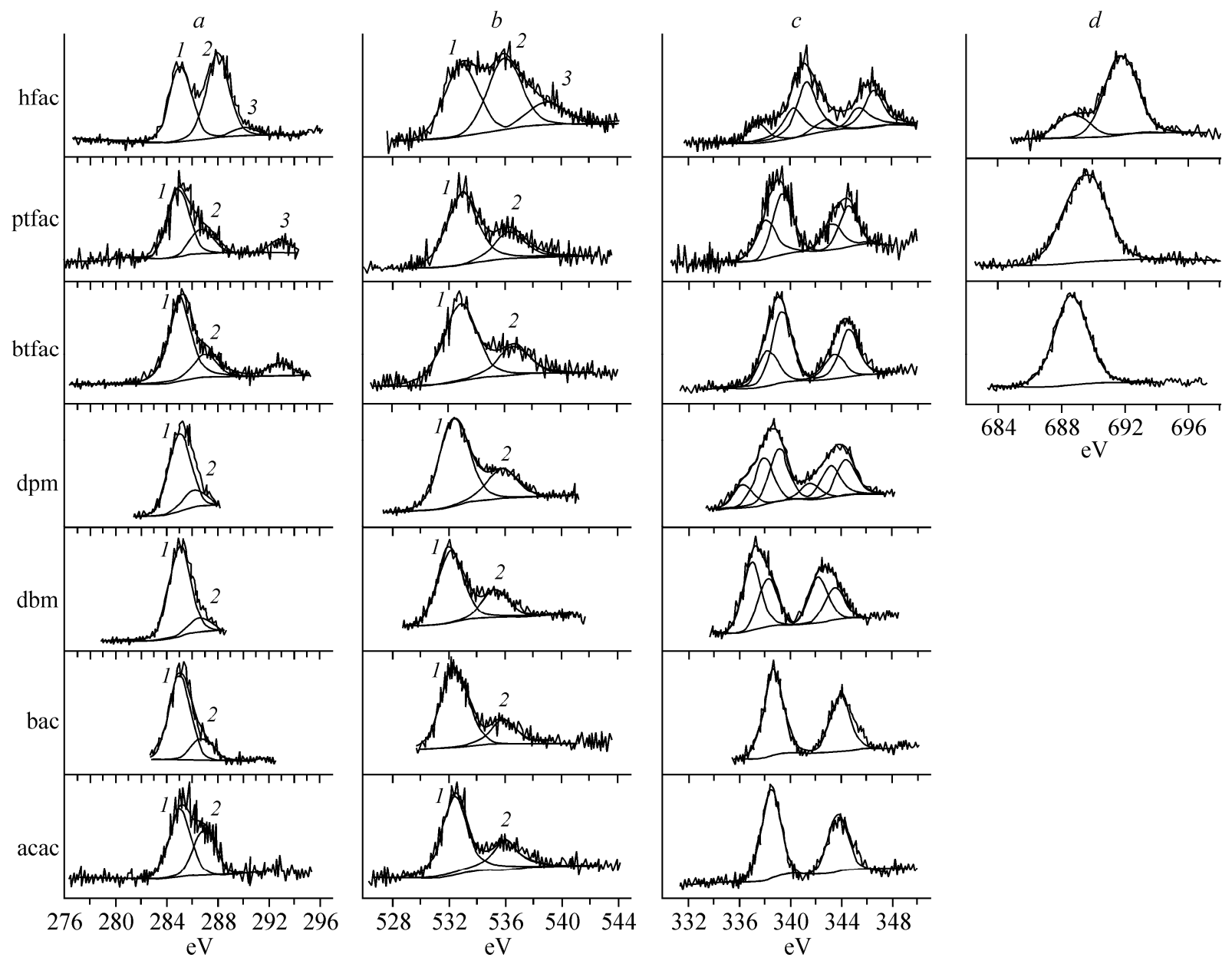

Fig. 1. X-ray photoelectron spectra of $\mathrm{Pd}(\mathrm{II}) \beta$-diketonates: $\mathrm{C} 1 s(a), \mathrm{O} 1 s(b), \mathrm{Pd} 3 d_{3 / 2,5 / 2}(c), \mathrm{F} 1 s(d)$. 


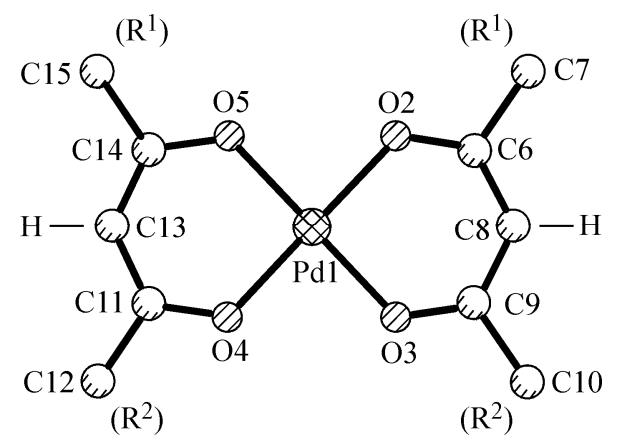

Fig. 2. Structural scheme and atomic numbering in $\mathrm{Pd}(\mathrm{II}) \beta$-diketonates.
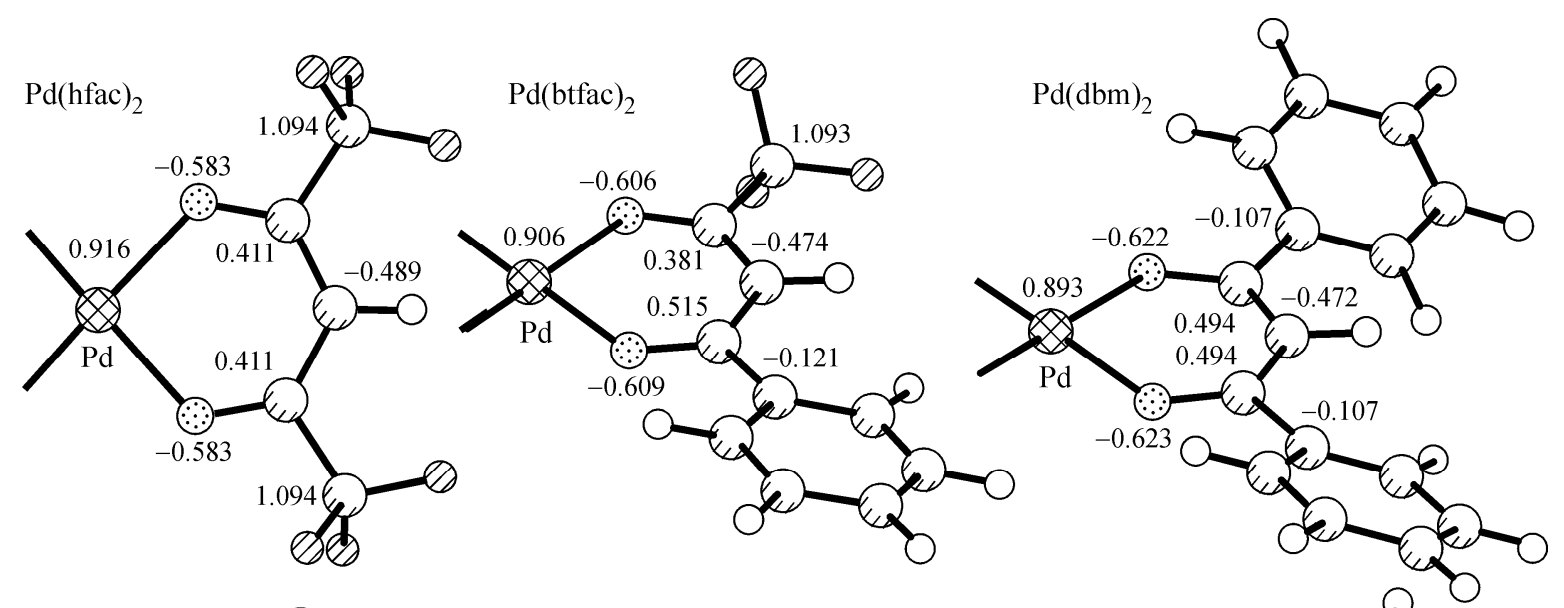

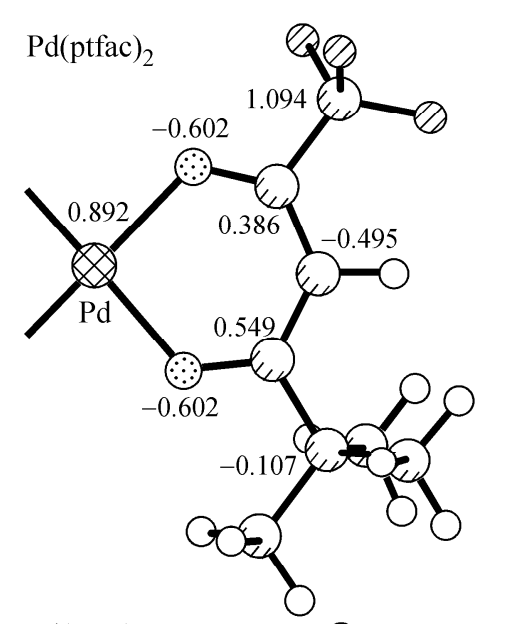

$\operatorname{Pd}(\mathrm{bac})_{2}$
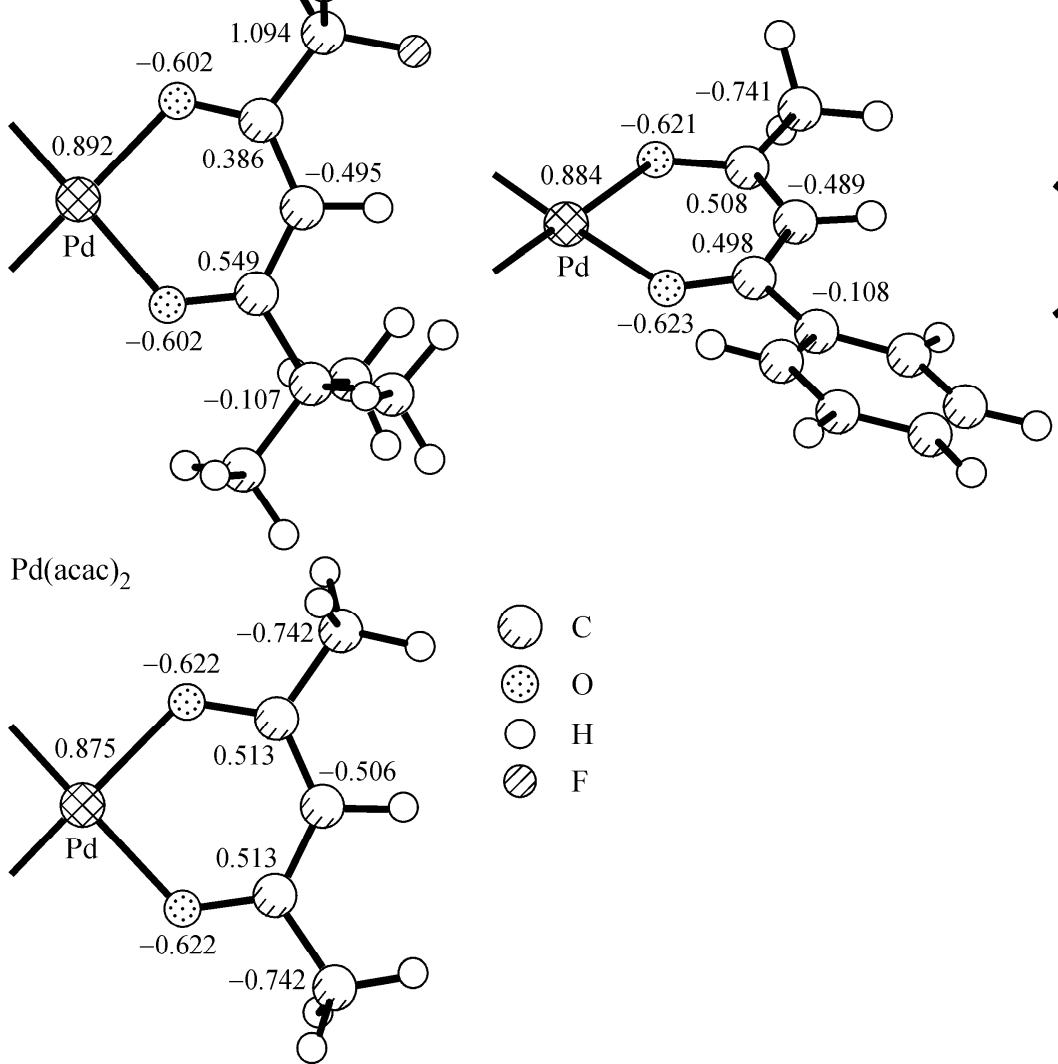

$\operatorname{Pd}(\mathrm{dpm})_{2}$

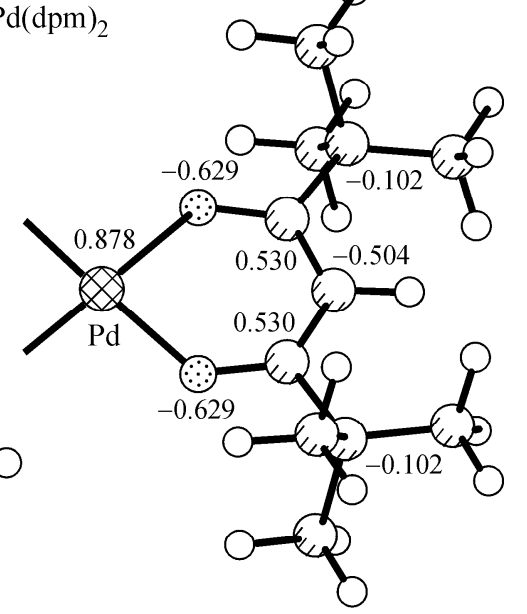

Q $\mathrm{C}$

O $\mathrm{O}$

$\mathrm{H}$

$\oslash \mathrm{F}$

Fig. 3. Charge distribution in palladium(II) $\beta$-diketonate molecules. 
TABLE 1. Calculated Binding Energies of the Core Levels $(E, \mathrm{eV})$ and Effective Charges on the Carbon, Oxygen, and Palladium Atoms

\begin{tabular}{|c|c|c|c|c|c|c|c|c|c|c|}
\hline \multirow{3}{*}{$\begin{array}{l}\text { Complex } \\
\operatorname{Pd}(\text { hfac })_{2}\end{array}$} & \multicolumn{4}{|c|}{$\mathrm{C} 1 s$} & \multicolumn{2}{|c|}{$\mathrm{O} 1 s$} & \multicolumn{2}{|c|}{$\mathrm{Pd} 3 d$} & \multicolumn{2}{|c|}{$\mathrm{F} 1 s$} \\
\hline & \multicolumn{2}{|c|}{ Group* } & \multirow{2}{*}{$\begin{array}{c}E \\
278.2\end{array}$} & \multirow{2}{*}{$\begin{array}{c}\text { Charge } q \\
-0.489\end{array}$} & \multirow{3}{*}{$\begin{array}{c}E \\
522.8\end{array}$} & \multirow{3}{*}{$\begin{array}{c}\text { Charge } q \\
-0.583\end{array}$} & \multirow{3}{*}{$\begin{array}{c}E \\
343.9\end{array}$} & \multirow{3}{*}{$\begin{array}{c}\text { Charge } q \\
0.916\end{array}$} & \multirow{3}{*}{$\begin{array}{c}E \\
672.9\end{array}$} & \multirow{3}{*}{$\begin{array}{c}\text { Charge } q \\
-0.35\end{array}$} \\
\hline & 1 & $\mathrm{CH}$ & & & & & & & & \\
\hline & 2 & $\mathrm{CO}$ & 280.8 & 0.411 & & & & & & \\
\hline \multirow{5}{*}{$\operatorname{Pd}(\mathrm{ptfa})_{2}$} & 3 & $\mathrm{CF}_{3}$ & 284.5 & 1.094 & & & & & & \\
\hline & 1 & $\mathrm{CH}$ & 277.2 & -0.495 & & & & & & \\
\hline & & $\mathrm{C}\left(\mathrm{CH}_{3}\right)_{3}$ & 278.0 & -0.107 & 521.8 & & 3121 & & & 035 \\
\hline & 2 & $\mathrm{CO}$ & 286.7 & $\begin{array}{l}0.386 \\
0549\end{array}$ & 521.9 & -0.602 & 343.1 & 0.892 & 672.5 & -0.35 \\
\hline & 3 & $\mathrm{CF}_{3}$ & 293.0 & $\begin{array}{l}0.549 \\
1.094\end{array}$ & & & & & & \\
\hline \multirow[t]{5}{*}{$\operatorname{Pd}(\mathrm{btfa})_{2}$} & 1 & $\mathrm{CH}$ & 277.3 & -0.474 & & & & & & \\
\hline & & $\mathrm{C}_{6} \mathrm{H}_{5}$ & 277.8 & -0.121 & & & & & & \\
\hline & 2 & $\mathrm{CO}$ & 280.0; & 0.381 & 521.8 & -0.609 & 343.0 & 0.906 & 672.5 & -0.35 \\
\hline & 3 & $\mathrm{CF}_{3}$ & 279.9 & 0.515 & & & & & & \\
\hline & & & 283.9 & 1.093 & & & & & & \\
\hline \multirow[t]{3}{*}{$\operatorname{Pd}(\mathrm{dpm})_{2}$} & 1 & $\mathrm{CH}$ & 276.4 & -0.504 & & & & & & \\
\hline & & $\mathrm{C}\left(\mathrm{CH}_{3}\right)_{3}$ & 277.5 & -0.102 & 521.0 & -0.629 & 342.3 & 0.878 & & \\
\hline & 2 & $\mathrm{CO}$ & 279.1 & 0.530 & & & & & & \\
\hline \multirow[t]{3}{*}{$\operatorname{Pd}(\mathrm{dbm})_{2}$} & 1 & $\mathrm{CH}$ & 276.6 & -0.472 & & & & & & \\
\hline & & $\mathrm{C}_{6} \mathrm{H}_{5}$ & 277.4 & -0.107 & 521.1 & $\begin{array}{l}-0.022 \\
-0.623\end{array}$ & 342.6 & 0.893 & & \\
\hline & 2 & $\mathrm{CO}$ & 279.3 & 0.494 & & & & & & \\
\hline \multirow[t]{4}{*}{$\operatorname{Pd}(\mathrm{bac})_{2}$} & 1 & $\mathrm{CH}$ & 276.6 & -0.489 & & & & & & \\
\hline & & $\mathrm{C}_{6} \mathrm{H}_{5}$ & 277.4 & -0.108 & & & & & & \\
\hline & & $\mathrm{CH}_{3}$ & 277.0 & -0.741 & 521.1 & -0.623 & 342.3 & 0.884 & & \\
\hline & 2 & $\mathrm{CO}$ & 279.3 & $\begin{array}{c}0.498 \\
0.508\end{array}$ & & & & & & \\
\hline \multirow[t]{3}{*}{$\operatorname{Pd}(\text { acac })_{2}$} & 1 & $\mathrm{CH}$ & 276.6 & -0.506 & & & & & & \\
\hline & & $\mathrm{CH}_{3}$ & 277.0 & -0.742 & 521.1 & -0.622 & 342.4 & 0.875 & & \\
\hline & 2 & $\mathrm{CO}$ & 279.3 & 0.513 & & & & & & \\
\hline
\end{tabular}

*The number of the group corresponds to the number of the decomposition component of the carbon $1 s$ spectra in Fig. 1.

respectively. The core level energies and effective (NBO) charges on atoms of the complexes were calculated within the framework of theoretical calculations (Table 1). Charge distribution is shown in Fig. 3.

\section{X-RAY PHOTOELECTRON SPECTRA OF THE COMPLEXES}

The experimental X-ray photoelectron spectra were decomposed into components by taking into account the stoichiometric composition of the compounds and the results of theoretical model calculations of core level energies and effective charges on the atoms of the complexes. Structure analysis (Figs. 2 and 3 ) showed that in the case of symmetric $\beta$ diketonates $\operatorname{Pd}(\mathrm{acac})_{2}, \operatorname{Pd}(\mathrm{dpm})_{2}, \operatorname{Pd}(\mathrm{hfac})_{2}$, and $\mathrm{Pd}(\mathrm{dbm})_{2}$, the chelate complex has three groups of carbon atoms: 1) $\left(\mathrm{C}_{6}, \mathrm{C}_{9}\right)$, $\left.\left.\left(\mathrm{C}_{11}, \mathrm{C}_{14}\right) ; 2\right)\left(\mathrm{C}_{8}\right),\left(\mathrm{C}_{13}\right) ; 3\right)\left(\mathrm{C}_{7}, \mathrm{C}_{10}\right),\left(\mathrm{C}_{15}, \mathrm{C}_{12}\right)$; and one group of oxygen atoms: 4) $\left(\mathrm{O}_{2}, \mathrm{O}_{3}\right),\left(\mathrm{O}_{4}, \mathrm{O}_{5}\right)$ whose charged states can differ. Table 1 lists theoretical estimates of the energies of the $\mathrm{C} 1 s$ levels for the corresponding groups of carbon atoms in the complexes. In all cases under study, one can expect that the experimental $\mathrm{C} 1 s$ spectrum will contain at least three components corresponding to the appropriate carbon groups. 
TABLE 2. Experimental Binding Energies of the Core Levels of the Carbon, Oxygen, and Palladium Atoms, eV

\begin{tabular}{|c|c|c|c|c|c|c|c|c|c|c|}
\hline \multirow{3}{*}{$\begin{array}{l}\text { Complex } \\
\mathrm{Pd}(\mathrm{hfac})_{2}\end{array}$} & \multirow{3}{*}{$\begin{array}{l}\text { Terminal radical } \\
\qquad \begin{array}{c}\mathrm{R}^{1}=\mathrm{CF}_{3} \\
\mathrm{R}^{2}=\mathrm{CF}_{3}\end{array}\end{array}$} & \multirow{3}{*}{$\begin{array}{c}\begin{array}{c}\text { Group of } \\
\text { complexes** }\end{array} \\
\text { III }\end{array}$} & \multirow{2}{*}{\multicolumn{2}{|c|}{$\mathrm{C} 1 s$}} & \multirow{2}{*}{\multicolumn{2}{|c|}{$\mathrm{O} 1 s$}} & \multicolumn{3}{|c|}{$\mathrm{Pd}$} & \multirow{3}{*}{$\begin{array}{c}\text { F1s } \\
688.7 \\
691.8\end{array}$} \\
\hline & & & & & & & \multicolumn{2}{|c|}{$3 d_{5 / 2}$} & $3 d_{3 / 2}$ & \\
\hline & & & $\begin{array}{c}1 * \\
2 \\
3 \\
\end{array}$ & $\begin{array}{l}285.0 \\
287.9 \\
290.0 \\
\end{array}$ & $\begin{array}{c}1 * \\
2 \\
3\end{array}$ & $\begin{array}{l}532.8 \\
536.0 \\
538.9\end{array}$ & $\begin{array}{c}1 * \\
2 \\
3\end{array}$ & $\begin{array}{l}337.6 \\
340.3 \\
341.3\end{array}$ & $\begin{array}{l}342.8 \\
345.5 \\
346.6\end{array}$ & \\
\hline $\operatorname{Pd}(\mathrm{ptfac})_{2}$ & $\begin{array}{c}\mathrm{R}^{1}=\mathrm{CF}_{3} ; \\
\mathrm{R}^{2}=\mathrm{C}\left(\mathrm{CH}_{3}\right)_{3} \\
\mathrm{R}^{1}=\mathrm{CF}_{3} ; \\
\mathrm{R}^{2}=\mathrm{C}_{6} \mathrm{H}_{5}\end{array}$ & II & $\begin{array}{l}1 \\
2 \\
3 \\
1 \\
2 \\
3 \\
\end{array}$ & $\begin{array}{l}285.0 \\
286.7 \\
293.0 \\
285.0 \\
287.0 \\
292.9 \\
\end{array}$ & $\begin{array}{l}1 \\
2\end{array}$ & $\begin{array}{l}533.0 \\
536.3 \\
\\
532.8 \\
536.6\end{array}$ & $\begin{array}{l}1 \\
2 \\
1 \\
2\end{array}$ & $\begin{array}{l}338.2 \\
339.4 \\
\\
338.3 \\
339.4\end{array}$ & $\begin{array}{l}343.4 \\
344.6 \\
343.5 \\
344.6\end{array}$ & $\begin{array}{l}688.2 \\
689.9 \\
688.6\end{array}$ \\
\hline $\operatorname{Pd}(\mathrm{dpm})_{2}$ & $\begin{array}{l}\mathrm{R}^{1}=\mathrm{C}\left(\mathrm{CH}_{3}\right)_{3} \\
\mathrm{R}^{2}=\mathrm{C}\left(\mathrm{CH}_{3}\right)_{3}\end{array}$ & & $\begin{array}{l}1 \\
2\end{array}$ & $\begin{array}{l}285.0 \\
286.1\end{array}$ & $\begin{array}{l}1 \\
2\end{array}$ & $\begin{array}{l}532.5 \\
535.8\end{array}$ & $\begin{array}{l}1 \\
2 \\
3\end{array}$ & $\begin{array}{l}336.3 \\
337.9 \\
339.1\end{array}$ & $\begin{array}{l}341.5 \\
343.2 \\
344.4\end{array}$ & \\
\hline $\operatorname{Pd}(\mathrm{dbm})_{2}$ & $\begin{array}{l}\mathrm{R}^{1}=\mathrm{C}_{6} \mathrm{H}_{5} \\
\mathrm{R}^{2}=\mathrm{C}_{6} \mathrm{H}_{5}\end{array}$ & I & $\begin{array}{l}1 \\
2\end{array}$ & $\begin{array}{l}285.0 \\
286.6\end{array}$ & $\begin{array}{l}1 \\
2\end{array}$ & $\begin{array}{l}532.1 \\
535.3\end{array}$ & $\begin{array}{l}1 \\
2\end{array}$ & $\begin{array}{l}336.9 \\
338.3\end{array}$ & $\begin{array}{l}342.2 \\
343.6\end{array}$ & \\
\hline $\operatorname{Pd}(\mathrm{bac})_{2}$ & $\begin{array}{l}\mathrm{R}^{1}=\mathrm{CH}_{3} ; \\
\mathrm{R}^{2}=\mathrm{C}_{6} \mathrm{H}_{5}\end{array}$ & & $\begin{array}{l}1 \\
2\end{array}$ & $\begin{array}{l}285.0 \\
286.7\end{array}$ & $\begin{array}{l}1 \\
2\end{array}$ & $\begin{array}{l}532.4 \\
535.8\end{array}$ & 1 & 338.7 & 344.0 & \\
\hline $\operatorname{Pd}(\mathrm{acac})_{2}$ & $\begin{array}{l}\mathrm{R}^{1}=\mathrm{CH}_{3} ; \\
\mathrm{R}^{2}=\mathrm{CH}_{3}\end{array}$ & & $\begin{array}{l}1 \\
2 \\
\end{array}$ & $\begin{array}{l}285.0 \\
286.9 \\
\end{array}$ & $\begin{array}{l}1 \\
2 \\
\end{array}$ & $\begin{array}{l}532.4 \\
535.9 \\
\end{array}$ & 1 & 338.5 & 343.8 & \\
\hline Pd metal & & & & & & & $\begin{array}{l}1 \\
2\end{array}$ & $\begin{array}{l}335.6 \\
337.6\end{array}$ & $\begin{array}{l}340.8 \\
342.9\end{array}$ & \\
\hline
\end{tabular}

*The number corresponds to the component of decomposition of the corresponding spectrum in Figs. 1 and 4.

$* *$ The complexes are grouped according to the number of fluoromethyl groups in the terminal radicals.

For asymmetric $\mathrm{Pd}(\mathrm{btfac})_{2}, \operatorname{Pd}(\mathrm{ptfac})_{2}$, and $\mathrm{Pd}(\mathrm{bac})_{2}$ complexes (Table 1), the energy of the $\mathrm{C} 1 s$ levels of the first group $\left[\left(\mathrm{C}_{6}, \mathrm{C}_{9}\right) ;\left(\mathrm{C}_{11}, \mathrm{C}_{14}\right)\right]$ is almost insensitive to the asymmetry of substituents $\left(\mathrm{R}^{1}, \mathrm{R}^{2}\right)$. The energy difference between the corresponding $1 s$ levels of the carbon atom varies within the limits of a few hundredths of an electron volt. Variation of the number of spectral components in the carbon spectra under study may only be due to the difference between the $\mathrm{C} 1 s$ energies for the atoms $\left[\left(\mathrm{C}_{7}, \mathrm{C}_{10}\right) ;\left(\mathrm{C}_{15}, \mathrm{C}_{12}\right)\right]$ of the $\mathrm{R}^{1}$ and $\mathrm{R}^{2}$ radical groups.

Using theoretical predictions of the number of components in the carbon and oxygen spectra and taking into account that the intensity of the components is proportional to the number of the corresponding atoms we decomposed the experimental spectra into components (Fig. 1). The half-widths of the individual components of the carbon spectra were fixed $(2 \mathrm{eV})$. Sample charging was taken into account using the most intense low-energy peak $(285.0 \mathrm{eV})$ assigned to the $\mathrm{CH}$, $\mathrm{C}\left(\mathrm{CH}_{3}\right)_{3}, \mathrm{CH}_{3}$, and $\mathrm{C}_{6} \mathrm{H}_{5}$ hydrocarbon groups. The maxima with the binding energies in the range $286.0-287.0 \mathrm{eV}$ in the carbon spectrum were assigned to the $\left[\left(\mathrm{C}_{6}, \mathrm{C}_{9}\right) ;\left(\mathrm{C}_{11}, \mathrm{C}_{14}\right)\right]$ carbon atoms from the first group (Table 2). The maxima with the binding energies 292.9-293.0 eV correspond to the carbon of the $\mathrm{CF}_{3}$ group.

Oxygen spectra. The most intense low-energy component with the binding energy $532.0-533.0 \mathrm{eV}$ was assigned to the oxygen atoms bonded to the Pd atom (Table 2). The line in the range 535.3-536.5 eV was attributed to oxygen adsorbed on the surface of the sample.

Fluorine spectra. The F1s spectra are singlets with a maximum at $688.0-689.0 \mathrm{eV}$ (Fig. 1). Table 2 lists the experimental energies of the $\mathrm{F} 1 s$ spectral lines for complexes with $\mathrm{CF}_{3}$ groups.

Quantitative analysis was performed using the integrated intensities of XPS lines corrected for atomic sensitivity (i.e., including atomic sensitivity factors, ASF) for a VG-Microtech spectrometer. The relative atomic concentrations and 
TABLE 3. Quantitative Analysis of the Composition of Pd $\beta$-Diketonate Complexes Based on X-ray Photoelectron Spectra

\begin{tabular}{|c|c|c|c|c|c|c|c|c|}
\hline \multirow{3}{*}{ Complex } & \multicolumn{4}{|c|}{$\mathbf{C}$} & \multicolumn{4}{|c|}{$\mathbf{O}$} \\
\hline & \multicolumn{3}{|c|}{ Experimental XPS data } & \multirow{2}{*}{$\begin{array}{l}\begin{array}{l}\text { Data of } \\
\text { formula }\end{array} \\
\begin{array}{l}\text { Stoichi- } \\
\text { ometry }\end{array}\end{array}$} & \multicolumn{3}{|c|}{ Experimental XPS data } & \multirow{2}{*}{$\begin{array}{l}\begin{array}{c}\text { Data of } \\
\text { formula }\end{array} \\
\begin{array}{l}\text { Stoichi- } \\
\text { ometry }\end{array}\end{array}$} \\
\hline & Atomic group & $\begin{array}{l}\text { Stoichi- } \\
\text { ometry }\end{array}$ & $\begin{array}{l}\text { Percent of } \\
\text { atoms, } \%\end{array}$ & & $\begin{array}{l}\text { Atomic } \\
\text { group }\end{array}$ & $\begin{array}{l}\text { Stoichi- } \\
\text { ometry }\end{array}$ & $\begin{array}{l}\text { Percent of } \\
\text { atoms, } \%\end{array}$ & \\
\hline \multirow[t]{3}{*}{$\operatorname{Pd}(\text { ptfac })_{2}$} & $\mathrm{CH}, \mathrm{C}\left(\mathrm{CH}_{3}\right)_{3}$ & 8.9 & 62.5 & 10.0 & & & & \multirow{3}{*}{4.0} \\
\hline & $\mathrm{CO}$ & 3.6 & 25.0 & 4.0 & d & 4.4 & 00.1 & \\
\hline & $\mathrm{CF}_{3}$ & 1.8 & 12.5 & 2.0 & Adsorb. 0 & 2.0 & 31.0 .3 & \\
\hline \multirow[t]{3}{*}{$\operatorname{Pd}(\mathrm{btfac})_{2}$} & $\mathrm{CH}, \mathrm{C}_{6} \mathrm{H}_{5}$ & 15.0 & 70.0 & 14.0 & & 4.1 & 67.0 & \multirow{3}{*}{4.0} \\
\hline & $\mathrm{CO}$ & 4.3 & 20.0 & 4.0 & Adsorb $\mathrm{O}$ & 20 & 33.0 & \\
\hline & $\mathrm{CF}_{3}$ & 2.1 & 10.0 & 2.0 & & & & \\
\hline \multirow[t]{2}{*}{$\operatorname{Pd}(\mathrm{dpm})_{2}$} & $\mathrm{CH}, \mathrm{C}\left(\mathrm{CH}_{3}\right)_{3}$ & 18.2 & 81.8 & 18.0 & $\mathrm{OC}$ & 3.9 & 69.3 & \multirow[t]{2}{*}{4.0} \\
\hline & $\mathrm{CO}$ & 4.0 & 18.2 & 4.0 & Adsorb. O & 1.8 & 30.7 & \\
\hline \multirow[t]{2}{*}{$\operatorname{Pd}(\mathrm{dbm})_{2}$} & $\mathrm{CH}, \mathrm{C}_{6} \mathrm{H}_{5}$ & 31.7 & 86.7 & 26.0 & $\mathrm{OC}$ & 4.0 & 66.2 & \multirow[t]{2}{*}{4.0} \\
\hline & $\mathrm{CO}$ & 4.9 & 13.3 & 4.0 & Adsorb. O & 2.0 & 33.8 & \\
\hline \multirow[t]{2}{*}{$\operatorname{Pd}(\mathrm{bac})_{2}$} & $\mathrm{CH}, \mathrm{CH}_{3}, \mathrm{C}_{6} \mathrm{H}_{5}$ & 17.5 & 80.0 & 16.0 & $\mathrm{OC}$ & 4.7 & 71.9 & \multirow[t]{2}{*}{4.0} \\
\hline & $\mathrm{CO}$ & 4.4 & 20.0 & 4.0 & Adsorb. O & 1.8 & 28.1 & \\
\hline \multirow[t]{2}{*}{$\operatorname{Pd}(\text { acac })_{2}$} & $\mathrm{CH}, \mathrm{CH}_{3}$ & 6.2 & 59.9 & 6.0 & $\mathrm{OC}$ & 4.8 & 69.2 & \multirow[t]{2}{*}{4.0} \\
\hline & $\mathrm{CO}$ & 4.1 & 40.1 & 4.0 & Adsorb. O & 2.2 & 30.8 & \\
\hline
\end{tabular}

percentage of components in the carbon and oxygen spectra have also been calculated. Table 3 gives atomic concentrations along with stoichiometric compositions for the compounds. Quantitative analysis of the $\mathrm{Pd}(\mathrm{hfac})_{2}$ complex could not be fulfilled because the compound decomposed under X-radiation during the experiment.

$\operatorname{Pd} 3 \boldsymbol{d}_{3 / 2,5 / 2}$ spectra. As is known, vacuum sublimation of $\beta$-diketonate complexes can lead to decomposition of the latter $[13,14]$. Compounds with trifluoromethyl substituents in the ligand proved to be the least stable complexes from the series under study. Thus $\mathrm{Pd}(\mathrm{hfac})_{2}$ liberates free ligands as gaseous compounds already at $20^{\circ} \mathrm{C}$, while $\mathrm{Pd}(\mathrm{acac})_{2}$ starts to decompose at $100^{\circ} \mathrm{C}$. Mass spectrometric study of decomposition of the complexes in the gas phase showed that decomposition can follow several routes and form light gaseous molecular products and radicals, as well as solid products containing metal atoms $[14,15]$. Decomposition processes result in unstable metal-containing particles. These particles, in turn, can decompose, liberating the metal atom or other stable metal-containing forms.

Therefore the experimental spectra were analyzed from the viewpoint of the presence of different chemical forms of the palladium atom. The spectra were decomposed into potential components, whose energy positions were compared with the energies of the corresponding lines of known palladium compounds $[7,16]$.

Metallic Pd. To evaluate the energy positions of the individual components in the $\operatorname{Pd} 3 d_{3 / 2,5 / 2}$ spectra of the complexes we recorded the $\operatorname{Pd} 3 d_{3 / 2,5 / 2}$ spectrum of low-disperse metallic palladium. According to our measurements, the fundamental peak (Fig. 4h, l) of metallic palladium had a binding energy of $335.5 \mathrm{eV}$ (Table 2), which agrees well with the literature data $(335.7-335.8 \mathrm{eV})[7,16]$. The spectrum of metallic palladium also showed an unintense short-wave component (2) with an energy of $\sim 337.6 \mathrm{eV}$, which was attributed (based on the data of [16]) to the oxide forms of palladium, PdO and $\mathrm{PdO}_{2}$, for which $E \sim 337.0 \mathrm{eV}$. The experimental width of the components of the observed doublet is $\Delta E=1.8 \mathrm{eV}$, the interdoublet distance is $\sim 5.3 \mathrm{eV}$, and the intensity ratio within the doublet is $I_{3 / 2} / I_{5 / 2}=1.45$.

$\operatorname{Pd}(\mathbf{a c a c})_{2}$. The $\operatorname{Pd} 3 d_{3 / 2,5 / 2} \mathrm{X}$-ray spectrum of the complex is shown in Fig. $4 g$. The spectrum has two components of spin doublet with an interdoublet distance of $5.2 \mathrm{eV}$ and with a width of $1.8 \mathrm{eV}$; intensity ratio within the doublet is $I_{3 / 2} / I_{5 / 2}=1.25$. The energy of the highly intense component 1 is $E\left(\operatorname{Pd} 3 d_{5 / 2}\right)=338.5 \mathrm{eV}$. Comparison with the spectrum of metallic palladium indicates that the binding energy of the $\operatorname{Pd} 3 d_{5 / 2}$ level for $\operatorname{Pd}(\mathrm{acac})_{2}$ is shifted $\sim 3.0 \mathrm{eV}$ toward high binding 

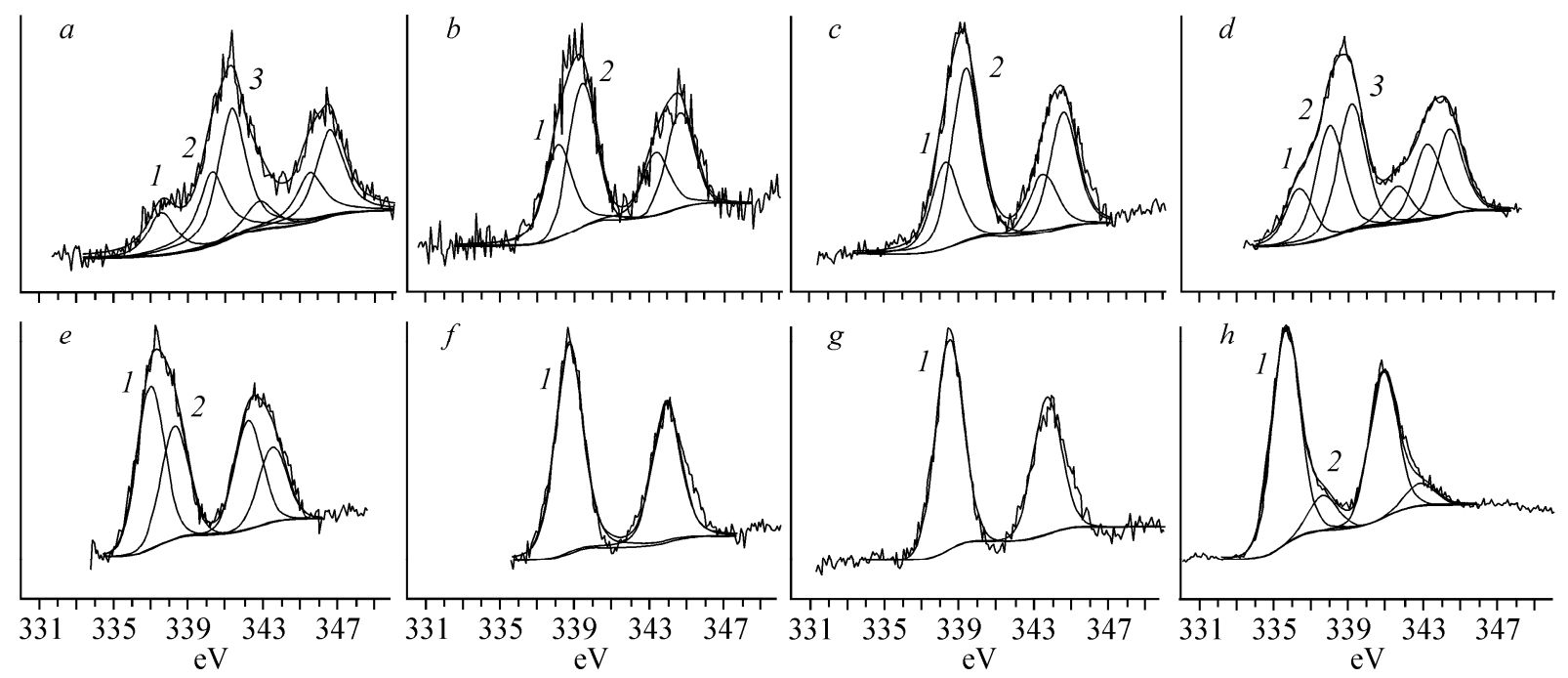

Fig. 4. $\operatorname{Pd} 3 d_{3 / 2,5 / 2} \mathrm{X}$-ray photoelectron spectra for $\operatorname{Pd}(\mathrm{hfac})_{2}(a), \operatorname{Pd}(\mathrm{ptfac})_{2}(b), \operatorname{Pd}(\mathrm{btfac})_{2}(c), \operatorname{Pd}(\mathrm{dpm})(d)$, $\operatorname{Pd}(\mathrm{dbm})_{2}(e), \operatorname{Pd}(\mathrm{bac})_{2}(f), \operatorname{Pd}(\mathrm{acac})_{2}(g), \operatorname{Pd}($ metal $)(h)$.

energies. The experimental spectrum has no line at $\sim 335.6 \mathrm{eV}$ corresponding to metallic palladium, which may be indicative of the compound not decomposed by X-radiation.

$\mathbf{P d}(\mathbf{b a c})_{2}$. The $\operatorname{Pd} 3 d_{3 / 2,5 / 2} \mathrm{X}$-ray spectrum of the compound is shown in Fig. $4 f$; in this case, $\Delta E=1.8 \mathrm{eV}$; interdoublet distance is $\sim 5.2 \mathrm{eV}$; intensity ratio within the doublet is $I_{3 / 2} / I_{5 / 2}=1.19$.

$\mathbf{P d}(\mathbf{h f a c})_{2}, \mathbf{P d}(\mathbf{p t f a c})_{2}$, and $\mathbf{P d}(\mathbf{b t f a c})_{2}$. For complexes with $\mathrm{CF}_{3}$ groups, both components of the $3 d_{3 / 2,5 / 2}$ spin doublet are much wider, $\sim 2.3 \mathrm{eV}$. Therefore the experimental spectra were decomposed into several components. For decomposition we used the parameters of the spectrum of pure metal. As can be seen, in the spectra of $\operatorname{Pd}(\mathrm{ptfac})_{2}$ and $\operatorname{Pd}(\mathrm{btfac})_{2}$ one can isolate two components (Fig. 4b, $c$; lines 1 and 2). The energy position of the long-wave component (1) $(338.2,338.3 \mathrm{eV})$ is close to the positions of the corresponding lines in the spectra of the complexes containing no $\mathrm{CF}_{3}$ groups (Table 2). The short-wave component (2) has a higher energy (339.4 eV, Table 2) for complexes with one trifluoromethyl group. Spectrum analysis of $\mathrm{Pd}(\mathrm{hfac})_{2}$ (Fig. 4a) shows three components with gradually increasing binding energies. The first two components $(1,2)$ have binding energies $(337.6,340.3 \mathrm{eV})$ close to those of complexes from groups I and II (Table 2).

Thus analysis of X-ray photoelectron spectra of $\mathrm{Pd}(\mathrm{II}) \quad \beta$-diketonate complexes has revealed destruction of complexes in the course of spectrum recording. $\operatorname{Pd}(\mathrm{acac})_{2}$ and $\operatorname{Pd}(\mathrm{bac})_{2}$ showed the least changes in composition. Complexes with $\mathrm{CF}_{3}$ groups decompose; the spectrum contains elements corresponding to metal-containing particles with a structure similar to that of complexes from the first group and with binding energies of $\sim 338.0-337.0 \mathrm{eV}$, and to particles containing $\mathrm{CF}_{3}$ radicals and having binding energies of $\sim 341.0-339.0 \mathrm{eV}$.

According to the data of X-ray photoelectron spectroscopy, complexes with hfac and dpm ligands are most liable to destruction; their spectra contain three types of component corresponding to different metal-containing particles of the compounds.

The experimental data on the chemical shifts of the core levels and the calculated data about the character of electron density distribution (effective charges) on the atoms of the complexes point to substantial differentiation of the charged states of atoms in the chelate ring. For different $R^{1}$ and $R^{2}$ radical groups, one can observe changes in the charged states of atoms and hence in the core level energies of atoms in the complex. Thus the energy position of certain lines in X-ray photoelectron spectra may be directly related to the charged state of the corresponding atoms.

From the theoretical (Table 1) and experimental (Table 2) data it can be seen that the presence of highly electronegative $\mathrm{CF}_{3}$ radicals in the complex leads to increased binding energy of the $3 d$ level of palladium, as indicated by the 


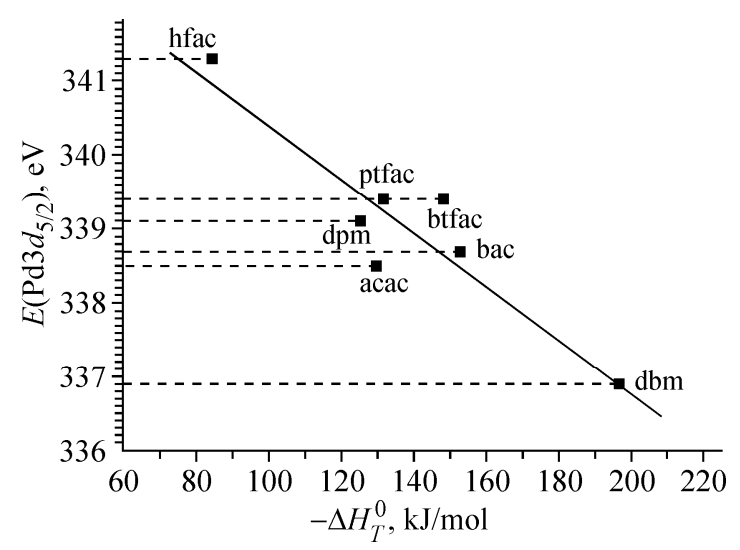

Fig. 5. Relationship between the binding energies of the $3 d_{5,2}$ core level of palladium in the complexes and sublimation enthalpies.

increased positive charge on the metal atom. Accordingly, the absolute energy of the O1s levels increases, which is also indicated by the decreased electron density on the oxygen atoms from the first coordination sphere of the central atom. Thus the presence of a $\mathrm{CF}_{3}$ group in the chelate ligand leads to increased ionicity of the $(\mathrm{M}-\mathrm{O})$ bond.

Figure 5 illustrates the correlation between the binding energy of the $3 d_{5 / 2}$ level of palladium (which is the central atom) and the sublimation heat $\Delta H_{T}^{0}$ of the appropriate complexes according to the data of [1]. Analysis of the core level energies shows correlation between $E\left(\operatorname{Pd} 3 d_{5 / 2}\right)$ and $\Delta H_{T}^{0}$ : the volatility of the complexes increases with the absolute energy of the level when the resulting electron density on palladium decreases (positive charge increases). Our previous XPS studies of copper and aluminum $\beta$-diketonates showed similar correlations [17].

\section{X-RAY PHOTOELECTRON SPECTRA AND INTERMOLECULAR INTERACTIONS}

The crystals of $\beta$-diketonate complexes of transition metals are commonly regarded as molecular crystals, in which the molecules are bound by van der Waals forces. The structural units (complexes) of the crystal are considered electrically neutral. Coulomb interaction is neglected [2]; still it is possible in the case of short contacts between complexes in molecular crystals. Therefore for different $\mathrm{R}^{1}$ or $\mathrm{R}^{2}$ substituents, changes in the charged state of atoms in the individual planar molecules of the crystal will affect the electrostatic component of the intermolecular interaction energy in crystal. Consequently, changes in the volatility of the complexes and hence in the sublimation enthalpy $\Delta H_{T}^{0}$ in the series of $\operatorname{Pd}(\mathrm{II})$ $\beta$-diketonate complexes under study will depend not only on van der Waals but also on electrostatic interactions of molecules in crystal.

The energy position of a core level of an atom in a complex depends on the electron density on the atom and on the nature of surrounding atoms and molecules, as well as on the spatial arrangement of the latter [7]. For isolated molecules, this dependence is generally defined by the relation

$$
E_{\text {bnd.mol. }}=k q_{\mathrm{A}}+\sum_{i \neq \mathrm{A}}\left(q_{i} / R_{i}\right)
$$

where $k$ is a constant that depends on the Coulomb interaction between the core and valence electrons; $q_{\mathrm{A}}$ is an effective charge on atom $\mathrm{A}$; and $R_{i}$ is the distance between the $i$ th atom and atom $\mathrm{A}$.

For Pd(II) $\beta$-diketonates under study (Fig. 3), the binding energies of the core levels of atoms from the complexes depend not only on charges on the atoms from the nearest surroundings (chelate ligands), but also on charges on other complex molecules that form the crystal lattice of the compound. Therefore relation (1) should take into account both 
Coulomb and multipole interactions of the core electrons of the atom with surrounding molecules:

$$
E_{\text {bnd }}=E_{\text {bnd.mol. }}+E_{\text {cryst }} \text {, }
$$

where $E_{\text {bnd.mol. }}$ is the energy defined by relation (1), and $E_{\text {cryst }}$ is the electrostatic interaction energy between the core electron of atom $\mathrm{A}$ and the charges and multipoles localized on the surrounding molecules in the crystal lattice. Thus the binding energies of the core electrons of atoms in the complexes and crystal substances will depend both on charge distribution in the individual molecules and on interactions between these molecules in crystals. Therefore one would expect certain correlations between the binding energies of the core levels of atoms and the interaction energies of complex molecules in the crystal lattice.

One possible correlation is shown in Fig. 5. It can be seen that the largest binding energy is observed for the $\mathrm{Pd}(\mathrm{hfac})_{2}$ complex, whose ligands contain highly electronegative radical groups $\mathrm{R}^{1}=\mathrm{R}^{2}=\mathrm{CF}_{3}$. As these radicals are replaced with more electronegative ones, $\mathrm{R}=\mathrm{CH}_{3}, \mathrm{C}\left(\mathrm{CH}_{3}\right)_{3}$, the core level energy of palladium decreases, while the enthalpy increases. Based on experimental data one can suggest the following. In the series of palladium $\beta$-diketonate complexes, increased binding energy of the core level of the metal indicates that charge density in the complex becomes substantially differentiated on passing to electronegative substituents; this will lead to greater electrostatic repulsion between adjacent molecules stacked in crystal and hence to lower vaporization enthalpy and greater volatility of the complexes. Thus increased net electron density (decreased energy of the $\mathrm{Pd} 3 d_{5 / 2}$ level) correlates with the increased vaporization enthalpy.

Substitution of alkyl by phenyl radicals in chelate ligands lowers the volatility of the compounds [13, 14] and hence leads to lower binding energies of the core levels of the metal atom and higher enthalpies (Fig. 5). The presence of the phenyl rings and formation of the corresponding type of molecular packing in crystals (stacks, nets) [2] give rise to additional intermolecular interactions in $\mathrm{Pd}(\mathrm{II}) \beta$-diketonate crystals, which involve the $\pi$ system of the $\mathrm{R}^{1}$ and $\mathrm{R}^{2}$ radicals and are evidently responsible for the decreased volatility of the complexes.

This work was supported by RFBR grant No. 03-03-32115.

\section{REFERENCES}

1. G. I. Zharkova, P. A. Stabnikov, V. M. Grankin, et al., Koordinats. Khim., 26, No. 8, 614-620 (2000).

2. P. A. Stabnikov, I. K. Igumenov, V. R. Belosludov, et al., Izv. Akad. Nauk SSSR, Ser. Khim. Nauk, 2, No. 1, 37 (1985).

3. G. I. Zharkova, I. K. Igumenov, and N. M. Tyukalevskaya, Koordinats. Khim., 14, No. 1, 67-74 (1988).

4. I. G. Kaplan, Introduction into the Theory of Intermolecular Interactions [in Russian], Nauka, Moscow (1982).

5. P. Hobza and R. Zahradnik, Intermolecular Complexes, Elsevier, Amsterdam (1988).

6. A. I. Kitaigorodskii, Molecular Crystals [in Russian], Nauka, Moscow (1971).

7. V. I. Nefedov, X-ray Photoelectron Spectroscopy of Chemical Compounds. Handbook [in Russian], Khimiya, Moscow (1984).

8. L. N. Mazalov, X-ray Spectra [in Russian], Institute of Inorganic Chemistry, Siberian Division, Russian Academy of Sciences, Novosibirsk (2003).

9. K. Siegbahn, K. Nordling, A. Fahlman, et al., ESCA. Atomic, Molecular, and Solid State, Nova Acta Regiae Societatis Scientarium Upsaliensis, Ser. IV, Vol. 20, Structure Studied by Means of Electron Spectroscopy, Uppsala (1967).

10. D. A. Shirley, Phys. Rev. B, 5, No. 12, 4709-4714 (1972).

11. Jaguar 6.5, Schrödinger Inc., Portland, OR (2005).

12. F. H. Allen and O. Kennard, Chem. Des. Autom. News., 8, 31-37 (1993).

13. A. F. Bykov, P. P. Semyannikov, and I. K. Igumenov, J. Therm. Anal., 38, 1463-1475 (1992).

14. P. P. Semyannikov, Extended Abstract of Chem. Sci. Cand. Dissertation, Institute of Inorganic Chemistry, Siberian Division, Russian Academy of Sciences, Novosibirsk (1988).

15. P. P. Semyannikov, V. M. Grankin, A. F. Bykov, and I. K. Igumenov, J. Physique IV, 5, C5205-5211 (1995).

16. C. D. Wagner, A. V. Naumkin, A. Vass, et al., NIST X-ray Photoelectron Spectroscopy Database into NIST Standard Reference Database 20, Version 3.4 (web version).

17. G. F. Khudorozhko, L. N. Mazalov, I. K. Igumenov, and Yu. V. Chumachenko, Koordinats. Khim., 6, No. 3, 358-360 (1980). 